\title{
Influence of Agricultural Wastes on Shear Strength Properties of Soil
}

\author{
Nik Daud Nik Norsyahariati ${ }^{1, a}$, Abdul Jalil Falil Nisa ${ }^{1}$, Muhammed Abubakar Sadiq ${ }^{1}$ and Ghafar Azmi \\ Juliana $^{1}$ \\ ${ }^{1}$ Department of Civil Engineering, Faculty of Engineering, Universiti Putra Malaysia, 43400, Serdang, Selangor, \\ Malaysia
}

\begin{abstract}
Fiber reinforced soil is an effective and reliable technique for improving strength and stability of subgrade soil. Many studies have been conducted to investigate the influence of randomly distribution fiber inclusions in soil. Agricultural waste fiber was chosen as it is cheap, locally available, bio-degradable and eco-friendly. For this study, coir fiber and palm oil fiber will be implemented. Three types of soil with different properties were used to be mixed with both fibers. The present work will be focused on the influence of $1 \%$ waste materials into soils in terms of physical, chemical, morphological and mineralogical properties of waste-soil mixture and its relationship to the shear strength properties. Test result indicates that with addition of both fibers, the optimum moisture content (OMC) increased and the maximum dry density (MDD) decreased. Fibers inclusion can significantly decrease and increased the cohesion and internal angle of friction of soils, respectively.
\end{abstract}

\section{Introduction}

Agricultural waste materials are too abundant nowadays due to high demand in food industry and increasing of housing area that lead to clearance of plantation area. Due to this condition, the oil palm and coconut waste will be generated more. If those waste did not have a proper management, it will brings negative impact to the environment. Process of altering some soil properties by different methods, either mechanical or chemical can be defined as soil reinforcement. This is due to produce an improved soil material which has all desired engineering properties. Soil generally been reinforced to increase their strength and durability or to prevent erosion and dust formation in soils. The main purpose of this soil reinforced is to hold under the design use conditions and for the design life of one project. The properties of soil reinforcement totally depend on soil testing.

Addition of fiber may affect the engineering properties of soil in few aspects. Fiber reinforced soil behaves as a composite material in which fibers of relatively high tensile strength are embedded in a matrix of soil. Shear stresses in the soil mobilize tensile resistance in the fibers, which in turn imparts greater strength to the soil. Fibers from agricultural waste materials (coconut coir and palm oil) are chose to be implemented in this study. Discrete fibers are simply added and mixed randomly with soil, like in mixing soil with cement, lime, or other additives [1]. It is more economical both in terms of cost and energy to increase the bearing capacity of the soil rather than going for deep foundation or

\footnotetext{
${ }^{a}$ Corresponding author : niknor@upm.edu.my
} 
raft foundation. Inclusion of randomly distributed fiber makes the soil mass homogenous and maintains the isotropy in strength [2]. According to [3] and [4], the used of coir fiber is very cost effective compared to other material in construction area such example in slopes and bunds. In addition, inclusion of fiber only changes the physical properties of soil and has no impact on the environment. The introduction of reinforcing elements in a soil mass increases the shear resistance of the medium [5]. Soil stabilization improves the workability and the durability of the soil. The objectives of this study are i) to determine the properties of soils and agricultural waste materials, ii) to investigate and analyses the influence of agricultural waste on soil shear strength properties.

\section{Materials and Methods}

\subsection{Materials}

There are three soil samples were used in this study. Two samples (Soil A and Soil B) were collected at Universiti Putra Malaysia (UPM), Serdang, Selangor area and another sample (Soil C) was taken from Klang, Selangor area. These samples were collected based on the surrounding and the land use. Disturbed sample was used in this study and those sample were collected by using shovel and keep it in plastic for avoiding losses of moisture content. All three samples are being air-dried before mixing with agricultural waste fibers (Figure 2) in order to study the influence of fibers in soil.

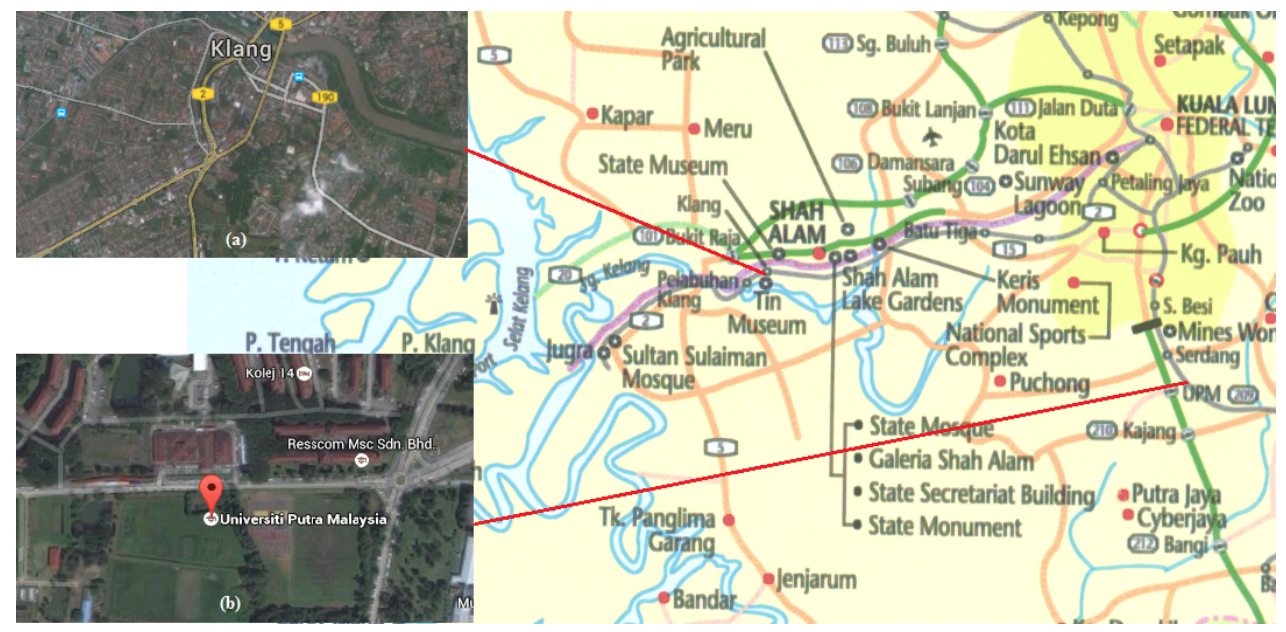

Figure 1. Sample location for soils used in this study (a) Klang site and (b) UPM site.

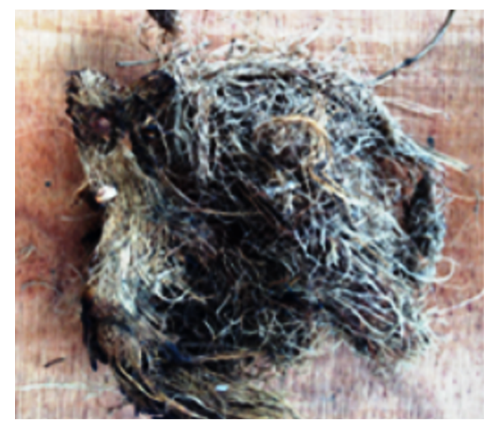

(a)

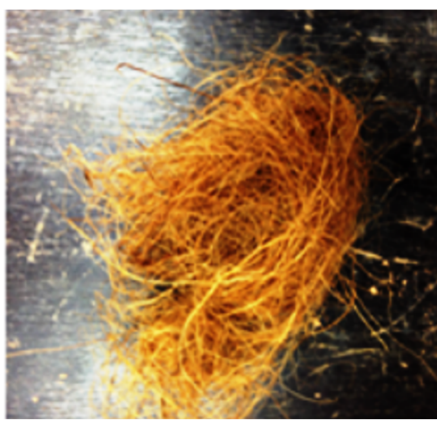

(b)

Figure 2. Agricultural waste fiber (a) palm oil fiber and (b) coir fiber. 


\subsection{Methods}

The reinforced soil specimens were prepared manually by mixing the dry soil, water and fibers. During the mixing process, the required amount of water was added to the soil prior to adding the fibers. Fibers were mixed manually with the wet soil at small increments. Particular care was taken to achieve satisfactory uniform mixtures. Soil sample with mix proportion of $0 \%$ and $1 \%$ of fibers by weight was prepared by referring to the previous study [6-8]. Then a few tests were conducted to obtain the properties of each waste-soil mixtures such as physical properties tests, chemical properties tests, structural and morphological tests and mechanical tests. Direct Shear Box test is used to determine the shear strength parameters of all soil samples used in this study with and without mixing fiber under undrained condition. All tests basically conducted accordance to [9].

\section{Results and Discussion}

\subsection{Physical properties}

Coir-stabilized lateritic soils, the maximum dry density of the soil decreases with the addition of coir and the value for optimum moisture content of the soil increases with an increase in percentage of coir [10]. With increasing the water content to the fiber reinforced, value of cohesion and suction decreased. Water plays an important role in lubricating layer on the interface of fiber and soil [1]. The increase of water content may also weaken the interfacial mechanical interactions between fiber and soil matrix and fiber will not capable to bear the tensile load. Thus, the increase of water content can induce a decrease of interfacial friction and cohesion.

Table 1. Basic properties for natural soils.

\begin{tabular}{|c|c|c|c|}
\hline \multirow[b]{2}{*}{ Properties } & Soil A & Soil B & Soil C \\
\hline & & & \\
\hline Moisture Content (\%) & 31.33 & 28.05 & 239.00 \\
\hline Specific Gravity & 2.19 & 1.77 & 1.29 \\
\hline $\begin{array}{l}\text { Grain size analysis } \\
\text { - } \quad \text { Gravel } \\
\text { - } \quad \text { Sand } \\
\text { - } \quad \text { Silt and clay } \\
\text { - } \quad \text { USCS } \\
\end{array}$ & $\begin{array}{c}33.2 \\
62.4 \\
4.4 \\
\text { SW }\end{array}$ & $\begin{array}{c}20.6 \\
66.8 \\
12.6 \\
\mathrm{SC}\end{array}$ & $\begin{array}{c}59 \\
38.2 \\
2.8 \\
\mathrm{Pt}\end{array}$ \\
\hline $\begin{array}{l}\text { Consistency limit } \\
\text { - } \quad \text { Liquid Limit (\%) } \\
\text { - } \quad \text { Plastic Limit (\%) } \\
\text { - } \quad \text { Plasticity Index (\%) } \\
\end{array}$ & $\begin{array}{c}47.6 \\
36.84 \\
10.76 \\
\end{array}$ & $\begin{array}{c}61 \\
34.01 \\
26.99 \\
\end{array}$ & $\begin{array}{c}120.4 \\
\text { Non plastic } \\
-\end{array}$ \\
\hline $\begin{array}{l}\text { Compaction study } \\
\text { - } \quad \mathrm{MDD}\left(\mathrm{Mg} / \mathrm{m}^{3}\right) \\
\text { - } \quad \mathrm{OMC}(\%) \\
\end{array}$ & $\begin{array}{l}1.38 \\
23.6\end{array}$ & $\begin{array}{l}1.46 \\
21.5\end{array}$ & $\begin{array}{l}0.72 \\
36.2\end{array}$ \\
\hline $\mathrm{pH}$ & 2.73 & 5.65 & 3.32 \\
\hline OC (\%) & 12 & 4.8 & 84.3 \\
\hline Specific Surface Area $\left(\mathrm{m}^{2} / \mathrm{g}\right)$ & 33.168 & 16.513 & 1.947 \\
\hline
\end{tabular}

Soil A can be classified as gravelly sands for having 33.2\% of gravel, $62.4 \%$ of sand and $4.4 \%$ of silt and clay. This soil is red in color and wide range in grain size with substantial amounts of intermediate particle sizes. Atterberg consistency limit tests carried out on the soil sample show that 
Soil A has liquid limit of $47.6 \%$, plastic limit of $36.84 \%$ and plasticity index of $11 \%$. The plots of plasticity index against liquid limit on the plasticity chart in Figure 3 showed Atterberg limits plot under "A" and it is in the zone of inorganic silts and very fine sand, clayey silts with slight plasticity. The soil is very firm and dry in place. For Soil B, grain size distribution shows it is clayey sands, sand-clay mixtures with $12.6 \%$ silt and clay, $66.8 \%$ sand and $20.6 \%$ gravel compositions. According to Unified Soil Classification System (USCS), this type of soil is medium in dry strength. Based on Figure 3, Soil B is in the zone of inorganic silts having liquid limit of $61 \%$, plasticity index of $27 \%$ and very low percentage of organic content with the value of $4.8 \%$. Mainly, consistency limits depends on the type and amount of clay fraction [11]. Soil $\mathrm{C}$ is readily identified by the color and odor that it is peat soil. Soil $\mathrm{C}$ is black in color and contains high organic matter content. The percentage of organic content showed that this soil has higher amount of organic matter which is $84 \%$. Peat normally formed from decomposed vegetation and well known for having difficulty on constructing road. Soil C is very high in moisture content that will lead to stability problem.

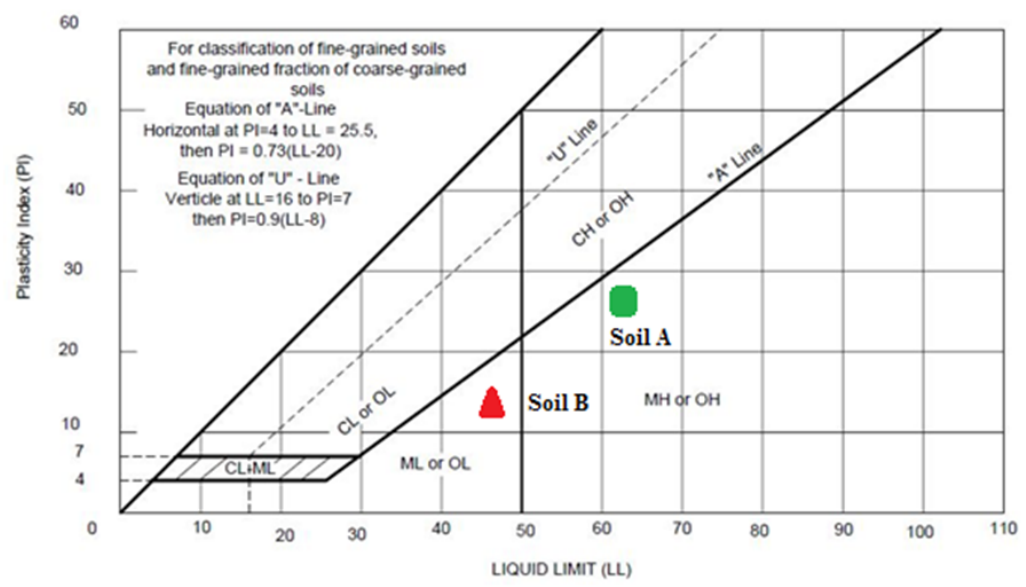

Figure 3. Particle size distribution of soils using in this study.

\subsection{Chemical properties}

The chemical compound in 1 gram of each type of soils and fibers are tested by using XRF equipment. The value of aluminium $\left(\mathrm{Al}_{2} \mathrm{O}_{3}\right)$ in soil $\mathrm{A}$ is $30 \%$ and $11 \%$ of iron $\left(\mathrm{Fe}_{2} \mathrm{O}_{3}\right)$. It is also contains large amount of silica $\left(\mathrm{SiO}_{2}\right)$. For soil $\mathrm{B}$, it showed that the highest element in this soil is silica about $46 \%$ and aluminium $24 \%$. Based on grain analysis, soil A has a high percentage of sand with silt and clay. Soil $\mathrm{C}$ contains $7 \%$ of silica and $2 \%$ of aluminium, which is very small amount compared to soil $\mathrm{A}$ and $\mathrm{B}$. However, soil $\mathrm{C}$ showed a high organic content among others. For fiber, both coir and palm oil fibre consists of aluminium, silica and calcium oxide compound. Coir fiber seems to have greater amount of silica about $45 \%$ compared to palm oil which having $7 \%$ silica.

\subsection{Morphological and mineralogical properties}

The mineralogical properties for each sample were determined by using X-ray diffractometer (XRD) equipment. Soil A contained kaolinite, gibbsite and quartz, Soil B contained quartz and muscovite and Soil $\mathrm{C}$ contained quartz and calcium strontium. The SEM images of the structure and morphology of the different samples are presented in Figure 4. These show the rough surface morphologies of the ground specimens. The SEM provided micrographs that show up bond formation, surface texture, mineral structure and geometry of the specimens. For laterite, it can be seen that the soil particles is attached to each other and rounded in shape. Flaky arrangements of clay can be seen as matrix between the fine grains. Soil is formed in stack of several layers in basic sheet units. These are 
generally flat and smaller in size, thus their surface areas per weight are large. From Figure 4, sample of peat have shown that the surface have porous granules of organic material. SEM analysis examined the surface topology of untreated fibers were shown in Figure 5. Coir fiber and palm oil fiber surface is covered with protrusions and with voided area left by detached protruded material. This porous surface morphology is useful for better mechanical interlocking of soil with the fiber.

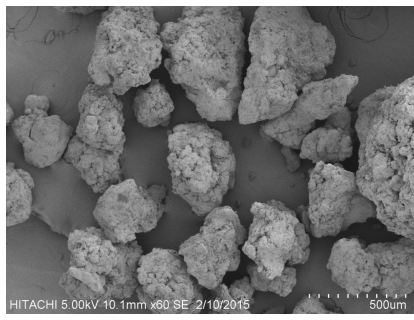

(a)

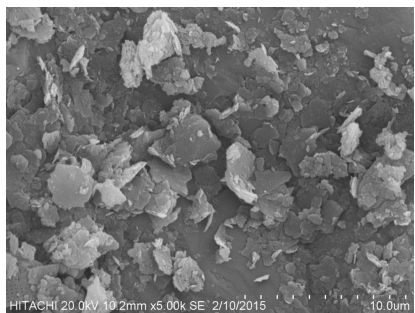

(b)

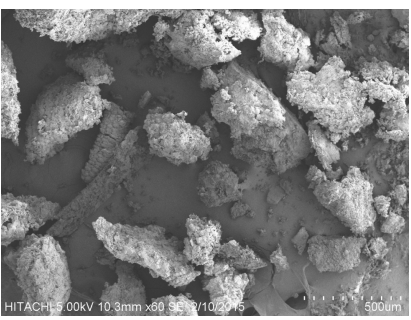

(c)

Figure 4. SEM images of natural soil (a) gravelly sand, (b) clayey sand and (c) peat.

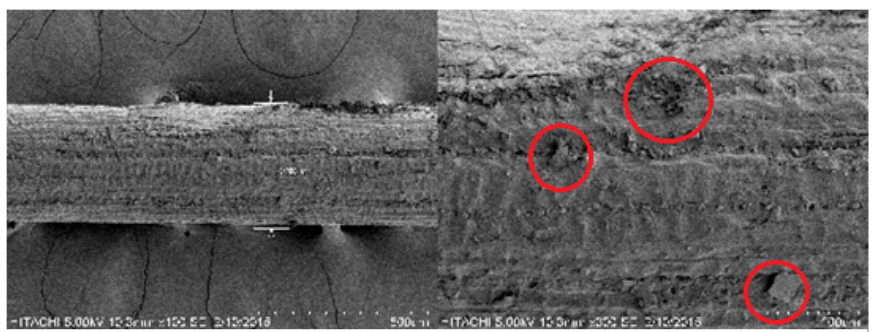

(a)

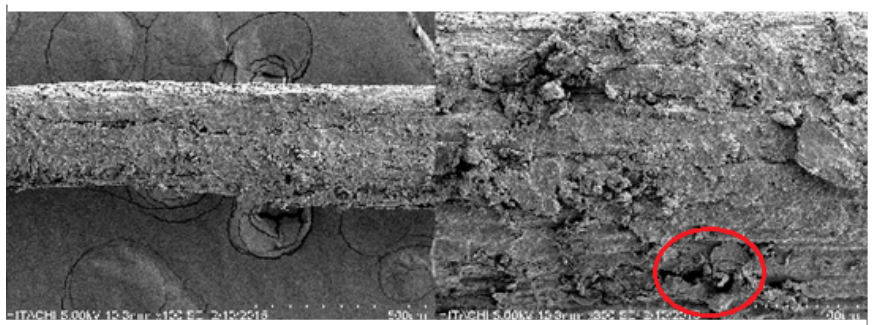

(b)

Figure 5. SEM images of natural fiber (a) coir fiber and (b) palm oil fiber.

\subsection{Shear strength properties}

The soil's shear strength parameters in terms of the internal friction angle and the cohesion value are evaluated and compared for the unreinforced and reinforced conditions of the soil sample. Table 2 shows the value of cohesion and angle of friction for each unreinforced and reinforced soil samples. It can be clearly seen that the inclusion of fibres increased the friction angle of soil. Coir-soil mixtures values for friction angle increased about $10 \%, 36 \%$ and $43 \%$ for laterite, clay and peat, respectively. Findings show that coir fibre exhibits greater enhancements in the strength of soil by having higher coefficient of friction [12]. Coir retains much of its tensile strength when wet and it has low tenacity but the elongation is much higher [13] and as for palm fiber, a constant palm fiber length, with increase in fiber inclusion, the maximum and residual strengths were increased [14]. It is observed that the palm fibers act to interlock particles and group of particles in a unitary coherent matrix thus 
the strength properties of soil can be increased [15]. In terms of cohesion, addition of $1 \%$ of both fibers into soil samples decreased the cohesion value and caused the soils less cohesion. It is believed that this happens due to the fibers separating soil particles. Singh and Mittal [7] conducted an experiment on the subgrade soil added with different ratios of coconut coir and found out that there is considerable improvement in compressive strength in case of all the soils on account of treatment with coconut coir fibre. Values of unconfined compressive strength are increase as more percentage of soil is replaced with coir fibre. It is noted that the compressive strength of soil increases when treated with coir fibre up to $1 \%$. It might be due to the increase in shear parameter. Fiber reinforcement benefit on the mechanical properties is governed by the interfacial friction and cohesion [16].

Table 2. Shear strength parameters.

\begin{tabular}{|l|c|c|c|}
\hline \multirow{2}{*}{ Type of Soil } & Fibre (\%) & \multicolumn{2}{|c|}{ Shear strength parameters } \\
\cline { 3 - 4 } & & c (kPa) & $\mathbf{0}^{\circ}$ \\
\hline \hline Laterite & $0 \%$ & 48.33 & 20.6 \\
& CF 1\% & 34.00 & 22.8 \\
& POF 1\% & 38.66 & 24.9 \\
\hline Clay & $0 \%$ & 19.33 & 22.1 \\
& CF 1\% & 15.66 & 30.0 \\
& POF 1\% & 18.66 & 29.0 \\
\hline Peat & $0 \%$ & 52.00 & 14.6 \\
& CF 1\% & 36.33 & 20.6 \\
& POF 1\% & 50.33 & 15.6 \\
\hline
\end{tabular}

\section{Conclusions}

Throughout the study, the used of fibres to treat or stabilize subgrade soils has been recognized, discussed and analyzed. The study was focused on determining the properties for waste-soil mixtures and investigating the influence of agricultural waste materials into soils for the purpose of subgrade works. These objectives were determined by conducting various laboratory tests on soil specimens with $1 \%$ of coir fibre and palm oil fibre. It can be summarized and concluded as follow: i) The optimum moisture content (OMC) for each soils increased with the inclusion of fibres due to the higher absorption ability of fibres. The maximum dry density (MDD) decreased when $1 \%$ fibres mixed with soils due to the soil being heavy in weight compared to fibre and was replaced by the light of weight fibre, and ii) The cohesion and angle of friction decreased and increased respectively with the inclusion of both fibres for all soil samples. The cohesion decreased due to the fibres acting as a separator for soil particles and causing less cohesion.

In conclusion, the properties for all waste-soil mixtures were determined and it showed that both fibres influenced the properties of each soils in terms of strength.

\section{Acknowledgement}

This study has been funded by Fundamental Research Grant Scheme-FRGS (No. 03-01-13-1172FR) granted by Ministry of Education (MOE), Malaysia. The help and assistance various governmental and non-governmental organizations in this study are gratefully acknowledged.

\section{References}

[1] J. Li, C. Tang, D. Wang, X. Pei and B. Shi, Effect of discrete fiber reinforcement on soil strength, J. of Rock Mechanics and Geotechnical Engineering, 6, 133-137, (2014).

[2] R.R. Singh and E.S. Mittal, Improvement of local subgrade soil for road construction by the use of coconut coir fiber, Int. J. of Research in Engineering and Technology, 3(5), 707-711, (2014). 
[3] B.M. Lekha, S. Goutham and A.U.R. Shankar, Evaluation of lateritic soil stabilized with arecanut coir for low volume pavements, Transportation Geotechnics, 2, 20-29, (2015).

[4] S. Vishnudas, H.H.G. Savenije, P.V.D. Zaag, K.R. Anil and K. Balan, The protective and attractive covering of a vegetated embankment using coir geotextiles, Hydrology Earth Syst. Sci., 10, 565-574, (2006).

[5] S. Akbulut, S. Arasan and E. Kalkan, Modification of clayey soils using scrap tire rubber and synthetic fibres, App Clay Sci, 38, 23-32, (2007).

[6] H.P. Singh and M. Bagra, Improvement in CBR value of soil reinforced with jute fiber, Int. J. of Innovative Research in Science, Engineering and Technology, 2, 3447-3452, (2013).

[7] R.R. Singh and E.S. Mittal, Improvement of local subgrade soil for road construction by the use of coconut coir fiber, Int. J. of Research in Engineering and Technology, 3 (5), 707 - 711, (2014).

[8] H.P. Singh, Effects of coir fiber on CBR value of itnagar soil, Int. J. of Current Engineering and Technology, 1283-1286, (2013).

[9] British Standard Institution, BS 1377 Methods of Test for Soils for Civil Engineering Purposes, London, (1990).

[10]U. Ravishankar and S. Raghavan, Coir stabilised lateritic soil for pavements, Indian Geotech. Conf., Ahmedabad, (2004).

[11]Y.A. Yeliz and K. Abidin, Method dependency of relationships between specific surface area and soil physicochemical properties, Applied Clay Science, 50, 182-190, (2010).

[12]R. Ayyar, R. Krishnaswamy and S. Vismanadham, Geosynthetics for foundations on swelling clay, Int. Work on Geotex, Bangalore, (1989).

[13] S. Babu and K. Vasudevan, Strength and stiffness response of coir fiber-reinforced tropical soil, J. Mater. Civil Eng., 20, 571-7, (2008).

[14]M. Marandi, H. Bagheripour, R. Rahgozar and H. Zare, Strength and ductility of randomly distributed palm fibers reinforced silty- sand soils, Am. J. Appl. Sci., 5, 209-20, (2008).

[15]Z. Jamellodin, Z. Talib, R. Kolop and N. Noor, The effect of oil palm fibre on strength behaviour of soil, The 3rd SANREM Conf, Kota Kinabalu, (2010).

[16]F. Ahmad, F. Bateni and M. Azmi, Performance evaluation of silty sand reinforced with fibers, Geotext Geomembr, 28, 93-9, (2010). 